\title{
Teaching Materials for International Chinese Language Teachers: Current Situation, Predicament and Development Path
}

\author{
Huang $\mathrm{Le}^{1, \mathrm{a}^{*}}$ \\ ${ }^{1}$ East China Normal University, Shanghai, China; Huzhou University, Huzhou, China \\ ahuangle@zjhu.edu.cn

\begin{abstract}
After nearly 60 years of exploration, the compilation of teaching materials for international Chinese teachers meets the requirements of teaching and teacher capacity training, follows the principle of "language-culture-practice". Under the new circumstances, the existing problems include: the number of training materials for international Chinese teachers is not enough, the intention of stratification is not obvious, the teaching materials suitable for localized teachers are few, and the degree of informatization and networking is not high. Faced with different needs, international Chinese teacher teaching materials should develop more teacher training materials, especially localized teacher training materials. At the same time, in the context of intelligent media, new ways of dissemination of teaching materials should be sought.
\end{abstract}

Keywords: international Chinese teachers, teaching materials, Chinese international education, localization

\section{国际汉语师资教材：现状、困境和发展路径}

黄乐 1 , a*

'华东师范大学国际汉语文化学院, 上海, 中国; 湖州师范学院人文学院, 浙江湖州, 中国 a huangle@zjhu.edu.cn

\section{摘要}

经过近 60 年的探索, 国际汉语师资教材的编写符合了教学和教师能力培养目标要求, 遵循了 “语言-文化-实 践” 相结合的原则, 并与心理学、教育学等多门学科相结合。在新形势和新的背景下, 所存在的问题包括: 国 际汉语教师的培训教材数量不多, 分层化意图不明显, 适用于本土化教师的教材少, 信息化、网络化程度不高。 面对不同需求，国际汉语师资教材应开发更多师资类尤其是本土化教师培训教材，同时在智媒化背景下，要寻 求教材资源传播新途径。

关键词: 国际汉语教师 教材 汉语国际教育 本土化

\section{1. 前言}

随着中国经济的发展和孔子学院项目的推进, 越 来越多的国家将汉语作为语言学习的课程之一, 根据 2018 年在成都举办的 “第十三届孔子学院大会” 统 计数据, 截至 2018 年 12 月, 我国在全球 154 个国家 (地区) 建立了 548 所孔子学院和 1193 个孔子课堂,
2018 年共有来自 196 个国家和地区的 492, 185 名各 类外国留学人员在全国 31 个省（区、市）的 1004 所 高等院校学习。2013 年, 国家主席习近平提出建设 “新丝绸之路经济带” 和 “ 21 世纪海上丝绸之路” 的合作倡议，国家实施 “一带一路” 政策，是以沿线 国家经济合作为主体, 共同打造政治互信、经济融合、 文化包容的利益共同体、命运共同体和责任共同体， 
在构建人类命运共同体的过程中, 语言是中外文化交 流的桥梁和枢纽。随着国家孔子学院的发展和政策的 推进, 越来越多的 “一带一路” 沿线国家留学生开始 学习汉语, 了解中国文化。2018 年 6 月在中柬建交 60 周年友好关系研讨会上, 两国对建立师范、语言 学、文学和翻译等四个方向的汉语硕士课程体系建设 进行了探讨; 2019 年 4 月在两国元首的见证下, 中 葡两国签订了《中国孔子学院总部与葡萄牙共和国教 育部关于在葡萄牙中学教育中开展汉语教学的合作 协议》, 葡萄牙将进一步在当地学校和社区推广汉语 教学和中华文化, 在葡萄牙高中学校的人文社会科学 课程和职业技术课程中开设汉语课程; 2012 年刚果 （布）设立了首所孔子学院, 使汉语成为当地人民青 睐的外语之一，2019 年 6 月中国与刚果共和国签署 了《关于合作建设冈波 - 奥利卢-革命中学孔子课堂 的协议》 ${ }^{1}$, 随着 “一带一路” 国家策略的推进, 留 学生的学习需求也持续增加。

《国家中长期教育改革与发展规划纲要 （2010-2020 年）》中明确提出要加强国际交流与合 作, 进一步扩大外国留学生规模。为促进世界优秀青 年更好地了解中国文化和语言, 孔子学院总部/国家 汉办设立了 “孔子学院奖学金” ，用来资助从事汉语 教育、汉语国际教育相关工作的优秀留学生攻读本科 和硕士学位, 2012 年 11 月启动了“孔子新汉学计划”, 用以培养来华攻读博士学位的研究生、访问学者等。 2021 年 11 月发布的《国务院办公厅关于全面加强新 时代语言文字工作的意见》中再一次强调了汉语国际 教育的重要作用, 意见指出: 要大力提升中文国际地 位和影响力, 吸引更多的海外中文教师来中国攻读中 文国际教育的硕博士学位。要加强国际中文教育和服 务, 加强中文在海外华文学校的推广应用, 加强海外 华文教师培训。国家的战略发展目标和孔子学院的发 展使国际汉语教师的需求持续增加。国家教委 1984 年批准设立对外汉语专业（2013 年改称 “汉语国际 教育” 专业），并从 1985 年和 1986 年起开始招收本 科学生和硕士研究生, 2007 年国家设置汉语国际教 育硕士专业学位, “2018 年国务院学位委员会办公 室批准招收汉语国际教育方向博士研究生, 使国际汉 语教师完成了从本科到专业硕士, 再到专业博士的完 整教师专业发展体系建构” “1]。汉语国际教育专业建 设完善的同时, 国家对国际汉语教师的培养也提出了 更高要求, 提高国际汉语教师的专业素养和教学能力 成为汉语国际教育的重要任务, 在汉语走向国际化的 的背景和新形势下, 国际汉语师资教材的编写和研究 也成为目前研究的重点。

基于此, 本文通过分析目前国际汉语师资教材编 写的基本状况, 了解国际汉语教师培养过程中对教材 的需求状况, 发现教材编写和出版中存在的问题, 探 求新时期和新的形势下国际汉语师资教材编写的新 路径。

\section{2. 国际汉语师资教材编写现状}

“国际汉语教师, 是从事汉语作为第二语言教学 工作的教师，国内对国际汉语教师的培训始于上世纪 60 年代” ${ }^{[2]}$ 。目前国际汉语教师既包括母语为汉语的 中文教师，也包括国外从事中文国际教育工作的教 师, 随着国际汉语教育事业的发展和留学生数量的增 多，国际汉语教师的数量也在逐年增加，在此期间， 为对国际汉语教师进行培养，国内外出版了一批培训 国际汉语教师的教材，此类教材在编写过程中，始终 注重与国际汉语教师的能力目标相结合, 从不同的角 度满足国际汉语教师培养的需要。

\section{1. 教材的编写遵循了“语言要素一文化一实 践”相结合的原则}

国际汉语教师应具备语言能力、跨文化交际能力 和语言教学能力, 因此国际汉语师资教材在编写的过 程中遵循了“语言要素一文化一实践”相结合的原则。 语言知识是国际汉语教师教学的基础, 也是留学生学 习汉语的重点内容, 因此在对教师进行培训的每个阶 段, 语言要素类的教材都是编写的重点教材。从语言 要素上来看, 教材的内容涉及到语言学的基础知识, 包括语音、词汇、语法等知识点和教学方法, 既有系 统讲解语言学要素的专业性教材, 如黄伯荣、廖序东 的《现代汉语》、王力的《古代汉语》、叶蜚声、徐 通铭的《语言学概论》等, 也有与教学相结合进行编 写的教材, 如齐沪扬的《对外汉语教学语法》、毛世 桢的《对外汉语语音教学》、吴中伟、马小玲的《词 汇与词汇教学》等, 这些教材是培训国际汉语教师的 基础和核心教材, 也是教师具备良好专业素养的前 提。

在对留学生的教学过程中, 国际汉语教师一方面 承担着传播中华文化的责任，另一方面针对不同国 家、不同语言的学生和多元的文化背景，也应该具有 跨文化交际能力。国家汉办组织学者编写了《中国地 理常识》、《中国文化常识》、《中外文化交流故事 从书》等一系列展示中国传统和中国文化的丛书，并 翻译成多国语言; 与跨文化交际相关的教材有商务印 书馆的《跨文化交际概论》、北京语言大学出版社的 《跨文化交际与第二语言教学》和外语教学与研究出 版社为专业硕士打造的教材《跨文化交际》等，这些 教材的编写为国际汉语教师在不同国家进行文化教 学提供了参考。

实践类教材包括三个方面的内容: 教学方法、教 学设计和案例教学。教学方法类的教材如鲁健䩀《对 外汉语教学激创法散论》、杨慧元《国际汉语教师课 堂教学法》，还有分技能的教学方法从书《国际汉语 教学听说教学方法与技巧》、《国际汉语教学词汇教 学方法与技巧》等, 教材从听、说、读、写四大方面 探讨了第二语言课堂教学技巧和运用方法, 如听说 法、情景法、直接法等。教学设计类的教材有崔永华 的《对外汉语教学设计导论》、廖建玲的《国际汉语 
教学设计》等, 这类教材围绕教学对象的分析、教学 目标的设定、教学环节的组织、教案设计、测试与评 估等方面编写, 对教师的课堂教学具有指导作用。第 三个方面是案例教学类教材, 包括叶军的《国际汉语 教学案例分析与点评》, 朱勇的《国际汉语教学案例 与分析》，以及由孔子学院、国家汉办主编的《国际 汉语教师经典案例详解》, 案例及分析类教材通过搜 集国内外国际汉语教师在世界各地不同语言背景、不 同课堂、不同情境下遇到的教学、文化、课堂等方面 的问题, 分析原因, 寻求解决方案。新手教师可以通 过案例分析, 快速进入教师角色, 经验丰富的教师可 以通过阅读案例, 将自己的教学法与教材中建议的方 法进行比较, 从而提高教学效果。

\section{2. 教材的编写与师资的培养目标和需求密 切相关}

早期我国的对外汉语教学事业处于起步阶段, 这 个阶段主要以培养在国内从事汉语国际教育的师资 为主, 因此在这个时期关于国际汉语教师的教材主要 有刘珣的《对外汉语教育学引论》、陈昌来的《对外 汉语教学概论》、程裕祯的《中国文化要略》等, 同 时还编写有与培训国际汉语教师基础语言知识相关 的《现代汉语》、《古代汉语》、《语言学概论》等 教材。1997 年北京语言文化大学出版社出版了《对 外汉语教学研究从书》, 较系统地提出了对外汉语教 学的教学方法、学科体系和知识体系, 这些教材让学 生在学习基础知识的同时, 也让他们了解对外汉语教 学的学科特性、第二语言教学的技能、语言测试、语 言学习与教学法的流派等, 同时也涉及了中国的文化 知识, 早期的教材成为培养国际汉语教师的经典教 材。

“2004 年全球首个孔子学院在韩国首尔揭牌, 2005 年 7 月首届世界汉语大会在北京举行, 标志着 中国对外汉语教学走向了世界” ${ }^{[3]}$, 国家汉办开始大 量选派对外汉语教师赴国外进行汉语教学, 传播中国 文化, 国际汉语教学的师资需求进一步扩大。2006 年, 商务印书馆组织教师编写了 《对外汉语教学专题 研究书系》、 《对外汉语专业本科系列教材》, 专门 用于培养对外汉语专业的本科生, 内容包括语言理 论、教学理论、教学法、教育史、语言测试、教学技 巧等, 如 《对外汉语教材研究》、《对外汉语教学理 论研究》、 《对外汉语文化研究》、《汉语作为第二 语言的学习者与汉语认知研究》等, 教材体系完善, 内容全面, 同时分语音、词汇、语法的教学研究, 教 材内容更加细化。考虑到国际汉语教师将走出国门进 行教学, 更多的教材涉及了文化和跨文化交际的内 容, 如《世界文化通论》、《跨文化交际概论》等。

从 2007 年汉语国际教育硕士专业的设置到 2018 年招收汉语国际教育方向博士研究生, 汉语国际教育 专业研究生的培养进入发展阶段, 2015 年外语教学 与研究出版社推出了《汉语国际教育硕士系列教
材・核心课教材》，这套教材中除了对语言知识、教 学技能和跨文化交际内容的强调之外, 增加了《国际 汉语教学案例分析与点评》, 书中通过真实的案例、 教学者的反思和学者的点评, 培养学生在国际汉语课 堂教学中发现问题、解决问题的能力。

通过分析可看出，国际汉语师资教材的发展与国 家发展汉语国际教育专业和对师资培养的需求是分 不开的, 在国际汉语教育起步阶段、孔子学院的发展 阶段、专业硕士的培养阶段都有系列教材推出, 促进 了国际汉语教师的培训和能力的提高。

\section{3. 跨学科和运用媒介进行现代化教学的教 材增多}

汉语国际教育涉及语言学、心理学、信息技术等 多学科、跨专业内容的研究, 在第二语言习得过程中, 留学生的学习动机、语言的感知、语言的加工模式、 人脑对语言信息的处理等方面成为研究热点, 因此与 之相关的教材逐渐增多。徐子亮的《汉语作为第二语 言教学认知心理学》系统地将心理学知识引入第二语 言学习, 对国际汉语教师了解学生学习过程中的认知 特点和心理规律具有促进作用, 江新的《对外汉语教 学的心理学探索》将心理学的实验研究应用于汉语教 学研究之中, 为国际汉语教师从事研究工作提供了新 的角度和研究方法。随着网络的发展和智媒时代的到 来, 汉语国际教育也从传统课堂走向了网络课堂, 信 息技术的运用增加了语言课堂的教学手段。信息技术 与汉语国际教育相结合的研究成果主要表现在三个 方面: 中介语语料库的建立和研究、网络平台的开发、 多媒体教学手段的运用, 相关的参考书目有《基于中 介语语料库的汉语句法研究》、《韩国留学生习得汉 语介词副词偏误分析- - 基于国别化汉语中介语语 料库的研究》、《汉语作为第二语言教学的教学技术 研究》、《汉语多媒体教学课件设计》等。

\section{3. 国际汉语师资教材编写的困境}

在改革开放近四十年时间里，国际汉语教师培训 教材编写经历了从探索到蓬勃发展的阶段, 随着专业 建设和专业体系的完善, 教材的编写也趋向系统性、 实用性和针对性，为汉语国际教育本科、硕博士专业 人才的培养提供了保障。目前国际汉语教育出现了新 趋势, 随着中国经济的发展和政治影响力的提升, 汉 语学习逐步出现国际化的趋势, 而要完成汉语国际化 的过程, 势必会出现 “学汉语的国别广泛化, 学汉语 的人数居高化, 汉语教学体系完善化, 汉语教学本土 化，汉语应用场合多样化，汉语在国际间媒介化的趋 势” ${ }^{[4]}$ ，在汉语国际化的新背景形式下，国际汉语教 师的培养是重要的一环, 用于培养国际汉语教师的教 材也应适应新的变化和发展，但目前还存在一些问 题。 


\section{1. 教材数量上: 师资培训教材总体数量偏少}

国家汉办在中山大学的国际汉语教材研发与培 训基地建立了全球汉语及中华文化教材的教材库， “搜集、整理全球汉语教材信息 17800 多册/种，涉 及 40 个国家的出版社和 56 种媒介语言” ${ }^{[5]}$, 其中用 于留学生课堂教学的教材占 $63.17 \%$, 非课堂教学的 读物、教师用书占 $36.83 \%$ ，用于培训国际汉语教师 和教师发展类用书仅占 $4.63 \%^{[5]}$ 。与为留学生学习汉 语开发的各类教材和读本相比, 专门用于教师培训类 的教材用书的占比很小，不足 $5 \%$, 针对 “一带一路” 沿线国家教师培训编写的教材则更少。

\section{2. 教材内容上: 培训本土化汉语教师的教材 缺乏}

““本土汉语教师”是指接受相当程度的汉语和 中华文化教育，具有在其本国教授汉语和中华文化 能力资质的教师” ${ }^{[6]}$ ，培养本土汉语教师是解决世界 各国国际汉语教师师资短缺和疫情下国际汉语教育 的重要途径。目前孔子学院总部、国家汉办针对 75 个国家的 278 所孔子学院开发了适合当地教学大纲 和考试标准的本土教材 834 套, 共计 1162 册, 这些 教材多以词汇、词典、语法教程、口语教程、HSK 练 习册、文化读本为主, 编写对象是所有学汉语的留学 生。在对俄罗斯、乌克兰、哈萨克斯坦等国家的本土 化汉语师资进行调查后发现, 这些国家在培训汉语教 师时使用的教材, 基本是和其它专业学习汉语的留学 生使用的教材一样, 例如《新实用汉语课本》、《当 代中文》、《汉语 900 句》等, 主要是将国内已有的 教师培训教材翻译成不同的语言。在培训本土化汉语 教师的过程中, 基本还是以教授汉语语言学知识为 主, 由于不同国家的文化背景和语言背景的限制, 教 材的编写更侧重于语言要素, 对文化和教学实践方面 的教材开发不够。

\section{3. 教材适用对象上：分层化意图不明显}

“从国际汉语教师成长过程来看, 国际汉语教师 分为生手教师、熟手教师和专家型教师” [7] ，不同教 师的课堂教学水平和认知风格也不同, 教师教学层次 不同, 对教材的需求就不一样; 从培养本土化国际汉 语教师的角度来看, 教师类型又分为小学、中学、大 学教师, 同时还有教学型教师、研究型教师和管理型 教师，教师类别不同，适用于培养教师的教材也应有 针对性。目前国际汉语师资教材编写较少考虑到教师 的专业成长过程和分层教学等方面, 因此就未能针对 不同阶段、不同类型的教师编写适合的教材。留学生 有不同的语言特征和文化特征, 学习习惯和学习特点 也不同，教师培训类教材应该认识到教师的差异性， 根据不同国别有针对性地开发教材。

\section{4. 教材的技术手段上：信息化、网络化程度 有待提高}

在信息和网络化时代，教育技术手段在教材编写 中的运用一方面能极大提高读者的兴趣, 增强学习效 果, 另一方面能跨越国界, 实现网络教学。目前国内 外开发的国际汉语师资教材正在积极适应社会的发 展, 为阅读者提供新的阅读手段, 运用较多的是提供 与教材配套的 PPT 资源和视频资源, 其中包括教学大 纲、教学课件、介绍类视频和教学资源的补充, 这些 资源的提供能实现教师使用教材时资源共享。随着 $5 \mathrm{G}$ 技术的运用和智媒时代的到来, 与教材配套的网 络资源如果仅限于电子教案和视频资源, 则不能满足 教师的需求。

\section{4. 国际汉语师资教材编写的新路径}

\section{1. 从国内到国外: 开发更多师资类尤其是本 土化教师培训教材}

“汉语真正走向国际化的核心标志是汉语教学 的本土化” “] 。而汉语教学要本土化, “必须要在汉 语教师、教材、教法、教学模式及教学标准等各个方 面逐步实现本土化或形成本土化特色” ${ }^{[8]}$ 。随着孔子 学院和孔子课堂数量的增长, 许多国家在外派留学生 到中国学习汉语的同时, 也在大力培养各国本土化的 国际汉语教师, 让汉语教育能够可持续发展, 形成一 支带不走的教师队伍。培养本土化教师的目标使本土 化教材的开发和编写成为亟需解决的问题, 目前国外 开发的教材多是 “通型教材” ，即通过将一本教材翻 译成各种不同的语言来进行教学, 教材编写者有的没 有海外教学经历, 或者只是在某一个或几个国家从事 过汉语教学, 并不能了解所有孔子学院的情况和留学 生的特点, “随着对外汉语教学市场的细分, 海内外 学习者需求的多样化, 通型教材的市场将会越来越 小，因此要根据不同国别、不同类型的海外学习者编 写不同的教材” ${ }^{[8]}$ 。

开发本土化师资培训教材, 首先应加强对教材编 写的顶层设计。可由中外语言交流合作中心、国家汉 办和国外教育机构共同协商, 对当地语言使用情况进 行调研, 了解当地汉语学习的语言态度和语言政策, 并结合当地教育特点、教师培养目标、文化特征等制 定本土化教师的培养标准，根据标准编写适用于培训 教师的教材。第二, 教材编写人员队伍的组建和培养, 应组建一支由国内语言学专家、孔子学院一线教师、 本土化汉语教育工作者为主力的教材编写队伍, 充分 了解不同国家的语言政策，根据不同国家的经济、政 治、文化, 结合学生的学习特点、教学目的、学习动 机等方面的特点, 编写适合本土化 师资培训教材。 第三, 在本土化国际汉语教师标准和考核标准的基础 上开发配套教材。本土化国际汉语师资教材的编写必 须建立在本土化教师标准的基础之上，根据培养本土 教师的知识目标、教学目标、能力目标来制定编著大 
纲, 规划教材编写框架。第四, 明确国内外教材开发 的差异性。崔希亮曾提出:一个好的本土教师应具备 “汉语言文字学知识、语言学理论知识、教学和学习 理论知识（尤其是第二语言习得知识）、中国文化和 中国社会历史知识、教育心理学知识、外语和学生母 国知识、关于中国的百科知识等” ${ }^{[9]}$ ，与国内的国际 汉语教师相比, 国外本土化国际汉语教师更应加强对 中国文化、中国国情、中国历史、汉语言文字的特点 等方面的培训, 这也是本土化国际汉语师资教材编写 的难点和重点之一。

\section{2. 从新手到熟手: 针对不同层级的教师编写 教材}

从课堂教学过程来看, 处于不同阶段的国际汉语 教师在教学水平、教学认知、教学风格和对知识的处 理等方面有较大的差异。国际汉语教师所教的学生来 自不同国家, 其文化背景和学习方式具有多样性, 同 时, 由于年龄层次、母语背景、学习动机和心理状况 的不同, 学习效果也有较大的差异。新手教师更注重 讲解语言知识, 关注教学方法, 而对学生的认知程度 不够, 熟手教师在教语言点的同时, 会分析学生的特 点和学习策略, 因材施教, 从而达到较好的教学效果。 因此在培养国际汉语新手教师时, 应该要帮助他们获 得跨文化交际知识和获得关于学习者的知识 ${ }^{[7]}$ 。从课 堂实践的角度来分析, 新手教师会以 “传授知识为中 心”, 以知识讲解为主, 按部就班地完成教学内容和 教学过程, 熟手教师则能实现 “以学生为中心” 的课 堂, 在课堂上, 学生是课堂的中心, 由学生去完成知 识的学习和内化, 教师只是课堂的组织者、评估者、 观察者和辅导者, 新手教师需要学习在课堂上如何转 换教师身份和功能。从对课堂的交际性功能的运用方 面来分析, 熟手教师更注重课堂的交际性策略, 明白 语言学习的目的是为了交际, 因此他们在课堂上能通 过提供真实的文本、设置真实的任务、利用信息差等 方式, 实现交际的目的。从以上几点分析可以看出, 新手教师在成长为熟手教师的过程中, 需要经过专业 的培训和指导, 而目前关于国际汉语教师培训类的教 材中, 注意到新手和熟手教师差别的编者不多, 因此 在编写教材的过程中, 也就没对此进行区分, 同时教 材中多是以讲解语言知识为主, 而教师更需要的是如 何帮助教师适应交际性课堂的教材。对新手教师, 可 开发案例类教材, 以国内外汉语教师真实的课堂实录 为案例, 教材内容包括语言点的教学, 文化的教学, 教学过程中遇到的突发问题和文化冲突的解决方式 等, 通过专家的分析, 帮助教师了解应对策略。针对 熟手教师则更多的是开发助力教师提升专业能力、提 高教学效果和培养教学研究能力的培训教材。随着国 际汉语教师培训的专业化和国际化，教师教材也应该 根据不同的国家不同层次教师的特点编写教材, 对教 师进行分层教学和培训, 能帮助新手教师尽快适应工 作角色, 提升熟手教师的教学水平。

\section{3. 从纸媒到智媒: 寻求教材资源传播的新途} 径

传统的阅读模式都是以书本纸张为媒介和载体, 随着科技的发展，网络和信息技术已经引入传播领 域, 人们阅读和获取知识的方式也逐渐 “智媒化” 。 相对于纸媒而言, 智媒时代的阅读模式首先能实现数 据和资源共享, 能分析读者的阅读兴趣和阅读需要, 同时在阅读过程中能接受读者反馈, 分析读者的阅读 水平, 实现内容的按需呈现。另一方面, 智媒时代的 阅读方式中, 除了文字的呈现方式，还能实现语音、 图片、视频、音乐等多种媒介方式的结合阅读, 提高 阅读者的兴趣。出版社可以利用网络平台, 开发在线 国际汉语师资教材, 音视频课程等内容。目前国内唐 风汉语教学平台经过八年的研发与实践, 形成了一套 汉语教育信息化云平台整体方案, 2009 年 6 月, “网 络汉语教师实训基地” 获得中国国家教育部立项, 并 在华中师范大学成立汉语教师培训基地, 网络课程围 绕日常视频课程、HSK 视频解析、多媒体与信息化手 段在日常教学中的应用、标准化成绩评测方法等方面 与教师进行交流互动, 为外派日本、智利、韩国等国 的汉语教师进行培训, 取得了较好的效果。2021 年 国家开放大学出版社编写了 “汉语国际教育本科系 列” 融媒体教材, 教材内容包括纸质教材、网络课程、 微视频, 读者能扫描进行在线学习, 探索了课堂面授 与自主学习多模式兼容的教材模式。

智媒时代对国际汉语教师类教材资源的开发可 以通过以下几种手段：首先是开发慕课平台。慕课平 台的开发既可以使用已有的纸质教材资源, 请专家学 者或优秀教师对教材内容进行讲解示范, 并录制配套 视频，也可以开发由文本、视频、音频相结合的新型 教材。其次是利用手机 APP 等方式, 开发教师培训软 件, 软件内容可以分为教材文本、视频学习、案例讲 解等模块, 手机 APP 能让教师达到随时学习、利用碎 片化时间学习的目的。第三是通过大数据, 搭建网络 平台, 通过大数据和机器算法, 了解教师的使用需求 和水平要求, 推送适合教师的教学内容, 能实现人机 互动、为教师量身定制适合的学习内容。

\section{5. 结论}

在经济一体化和网络全球化的趋势下, 加之后疫 情时代人们对智媒平台的广泛接受和利用, 势必会给 学习方式和教材编写带来新的改革, 国际汉语师资教 材的编写一方面要适应国际形势的变化, 开发更多的 融媒体教材, 建立 “教师-网络平台一学生” 等新的教 学模式, 另一方面要分层级、分国别开发教材, 让国 际汉语师资培训教材更具有针对性。在开发融媒体教 材过程中, 除了语言学专家对教材的提纲和内容进行 编写之外, 还需要跨学科合作, 由专业人员搭建网络 平台和进行技术指导，建立包括课程视频播放、作业 提交、师生互动、教学反馈、数据分析等多方面的网 络学习平台。在分层级和分国别的教材开发中, 需要 
国内专业教师和不同国家本地汉语教师之间的沟通 和配合, 充分调研不同国家的教学要求、办学条件、 学生的学习特点、当地的文化习俗等, 编写适用于当 地的教材。因此, 国际汉语教师师资教材的编写既要 适应于国际形势的需要, 也要与教师的教学特点、教 师所在国家的教学特点相结合, 教材的开发任务任重 道远, 需要建立新的教材编写标准, 编写有针对性的 教材, 探索适合培训本土化教师的教材模式。

\section{项目基金}

本文为国家留学基金委资助项目 (项目编 号：202008330253）阶段性成果。

\section{REFERENCES}

[1] Ye Jun.(2018)The Development Track of International Chinese Teacher Education.International Chinese Language Education,3(04):36-46.

[2] Liu Xun.(1996)Several Issues Concerning the Training of Chinese Teachers.Chinese Teaching in the World,36:100-105.

[3] Wu Yongyi.(2018)Research Gleaning of CSL/CFL Pedagogy in the Past 40 Years.International Chinese Language Education,3(04):47-62.

[4] Li Quan\&Zhang Haitao.(2014)The connotation, trend and trategies of the internationalization of Chinese.Applied Linguistics,02:107-117.

[5] Zhou Xiaobing. ( 2018 ) An Overview of the Development of International Chinese Teaching Materials for 40 Years.International Chinese Language Education,3(04):76-91.

[6] Li Dongwei.(2014)An Important Strategy to Solve the Problem of Lacking Chinese Teachers All over the World: the Training of Native Chinese Teachers in Foreign Countries.Journal of Research on Education for Ethnic Minorities,25(05):53-58.

[7] Jiang Xin\&Hao Lixia.(2011)The Practical Knowledge of Novic eand Experienced Teachers of Chinese as a Second Language, 02:1-8

[8] Wang Jianqin.(2008)The Language Standards of the International Promotion of Chinese Language and the Competitive Strategie.Language Teaching and Language Research,01:65-72.

[9] Cui Xiliang. (2010) On the "Three Concerns" of Teaching Chinese as a Second Language.Chinese Teaching in the World,24:73-81. 